\title{
Breast-feeding, rapid growth in the first year of life and excess weight at the age of 2 years: the 3D Cohort Study
}

\author{
Lise Dubois ${ }^{1, *}$, Cindy Feng ${ }^{1,2}$, Brigitte Bédard', Yamei Yu ${ }^{1}$, Zhong-Cheng Luo ${ }^{3,4}$, \\ Isabelle Marc ${ }^{5}$ and William D Fraser ${ }^{3,6}$ \\ 'School of Epidemiology and Public Health, University of Ottawa, Ottawa, ON K1G 5Z3, Canada: ${ }^{2}$ Department of \\ Community Health and Epidemiology, Dalhousie University, Halifax, Canada: ${ }^{3}$ Sainte-Justine Hospital Research \\ Center, University of Montreal, Montreal, Canada: ${ }^{4}$ Department of Obstetrics and Gynecology, Prosserman Centre for \\ Population Health Research, Lunenfeld-Tanenbaum Research Institute, Mount Sinai Hospital, Faculty of Medicine, \\ University of Toronto, Toronto, Canada: ${ }^{5}$ Centre de recherche du CHU de Québec, Université Laval, Québec, Canada: \\ ${ }^{6}$ Centre de recherche du Centre hospitalier universitaire de Sherbrooke, Sherbrooke, Canada
}

Submitted 5 May 2021: Final revision received 8 November 2021: Accepted 4 January 2022: First published online 7 January 2022

\begin{abstract}
Objective: To assess relationships between breast-feeding, rapid growth in the first year of life and overweight/obesity status at the age of 2 years.

Design: As part of an observational, longitudinal study beginning in early pregnancy, multivariable logistic regressions were used to assess associations between breast-feeding duration (total and exclusive) and rapid weight gain (RWG) between birth and 1 year of age, and to determine predictors of overweight/obesity status at the age of 2 years.

Setting: Nine hospitals located in the province of Quebec, Canada.

Participants: A sample of 1599 term infants who participated in the 3D Cohort Study.

Results: Children having RWG in the first year and those having excess weight at the age of 2 years accounted for $28 \%$ and $<10 \%$, respectively. In multivariable models, children breastfed $<6$ months and from 6 months to $<1$ year were, respectively, 2.5 times (OR 2.45; $95 \%$ CI 1.76, 3.41) and 1.8 times (OR 1.78; $95 \%$ CI $1 \cdot 29,2 \cdot 45)$ more likely to show RWG up to 1 year of age compared to children breastfed $\geq 1$ year. Children exclusively breastfed $<3$ months had significantly greater odds of RWG in the first year (OR 1.94; $95 \%$ CI 1.25, 3.04) compared to children exclusively breastfed for $\geq 6$ months. Associations between breast-feeding duration (total or exclusive) and excess weight at the age of 2 years were not detected. RWG in the first year was found to be the main predictor of excess weight at the age of 2 years (OR 6.98; $95 \%$ CI 4.35, 11.47).

Conclusions: The potential beneficial effects of breast-feeding on rate of growth in the first year of life suggest that interventions promoting breast-feeding are relevant for obesity prevention early in life.
\end{abstract}

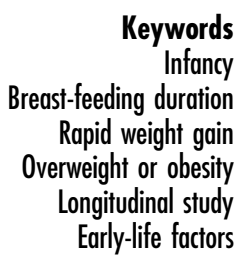

eywords a

Rapid weight gain Overweight or obesity Early-life factors
The first $1000 \mathrm{~d}$ of life (i.e. from conception to 2 years of age) constitute a period when human beings are exposed to influences that may have long-lasting effects on health $^{(1,2)}$. Since obesity has become a major public health concern worldwide ${ }^{(3,4)}$, identifying how modifiable earlylife risk factors influence young children's weight status is of utmost importance for designing relevant prevention initiatives as early as possible. Children who experienced rapid growth in infancy or who were already overweight in their early years appear to be at higher risk of excess weight later in life $e^{(5-7)}$.

Infant feeding practices are among modifiable early-life factors that have the potential to influence both the rate of growth and weight status during the first 2 years ${ }^{(6,8)}$. Both the WHO and Canadian public health and professional organisations have made recommendations on infant feeding that include exclusive breast-feeding for the first 6 months of life and continuous breast-feeding thereafter,

*Corresponding author: Email ldubois@uottawa.ca

(C) The Author(s), 2022. Published by Cambridge University Press on behalf of The Nutrition Society. This is an Open Access article, distributed under the terms of the Creative Commons Attribution-NonCommercial-NoDerivatives licence (https://creativecommons.org/licenses/by-nc-nd/4.0/), which permits non-commercial re-use, distribution, and reproduction in any medium, provided the original work is unaltered and is properly cited. The written permission of Cambridge University Press must be obtained for commercial re-use or in order to create a derivative work. 
up to the age of 2 years or older, along with the gradual introduction of complementary foods ${ }^{(1,9)}$. Although breast-feeding has a number of known benefits, controversies regarding its role in preventing overweight and obesity persist $^{(10,11)}$. Over the years, numerous studies have examined the relationship between breast-feeding and weight status during childhood, adolescence and even later ${ }^{(12-18)}$. Few studies, however, have investigated this association in children aged as young as 2 years while taking breastfeeding recommendations and early growth into account. The present study will assess the relationship between breast-feeding duration on the one hand and rapid growth in the first year of life and overweight/obesity status at the age of 2 years on the other hand, while considering other important early-life risk factors (i.e. infant sex, birth weight and gestational age at birth; maternal smoking during pregnancy; gestational diabetes; prepregnancy maternal weight status; caesarian delivery; parity; maternal age, education and immigrant status; and household income). We hypothesise that breast-feeding practices that comply with current guidelines during the first year (i.e. exclusive breast-feeding for 6 months and continuous breast-feeding thereafter) have protective effects on rapid growth during the first year and on overweight and obesity at the age of 2 years.

\section{Materials and methods}

\section{Study population}

Our study relies on data collected as part of the 3D Cohort Study, an observational, longitudinal study that covers the prenatal period. Details about rationale and objectives, recruitment, and data collection procedures were reported in an earlier publication ${ }^{(19)}$. In brief, the 3D Cohort Study enrolled 2366 pregnant women from May 2010 to August 2012. The women received care in nine urban obstetric clinics in the province of Quebec, Canada. The study was designed primarily to investigate how exposures to various risk factors during pregnancy were related both to adverse birth outcomes and to health status and early childhood development. An exhaustive array of prenatal and neonatal data was collected in the first, second and third trimesters of pregnancy and at delivery. The children participated in postnatal follow-up assessments at 3 months, 1 year and 2 years.

Our analyses exclude children with gestational ages $<37$ weeks at birth. Overall, the study includes 1599 term infants for whom detailed information on growth in the first year and/or weight status at the age of 2 years (Fig. 1) was available. A comparison of maternal characteristics in the original cohort indicates that the sample selected for analysis included fewer mothers with low educational attainment (secondary school or less: $7 \% v .10 \%, P=0.004$ ) and low-income levels $(<\$ 60000: \quad 27 \% \quad v$. $32 \%$, $P=0 \cdot 008)$, as well as fewer immigrant mothers (30\%v
$35 \% ; P=0.003$ ). Our analyses did not detect significant differences for other perinatal characteristics such as maternal age, parity, gestational diabetes, maternal smoking during pregnancy, maternal overweight/obesity status, mode of delivery, infant sex and birth weight (see online supplementary material, Supplemental Table 1).

\section{Infant feeding practices}

We obtained data on feeding practices from face-to-face interviews with mothers during the first two postnatal visits, which occurred at approximately 3 months and 1 year of age. On both occasions, the same series of questions were asked about breast-feeding initiation and duration. Questions concerning the introduction of commercial infant formula, other kinds of milk and complementary foods were also included in the interviews. Data collected retrospectively during the first year of life made it possible to derive categorical variables relating to (1) total breastfeeding duration (i.e. the period when the child received breast milk, whether or not other liquids or solids were also offered to the child), and (2) exclusive breast-feeding duration (i.e. the period when the child was fed only breast milk, to the exclusion of all other foods and liquids, such as water, infant formula, cow's milk and other beverages).

\section{Antbropometric measurements}

Birth weight was obtained from birth records. During postnatal visits, children's weight and length/height were measured according to a standardised protocol, using a medical scale and infantometer (for length in the first year) or stadiometer (for height at the age of 2 years). For both weight and height, two measures were taken. A third measure was added if the difference between the first two measures was $\geq 0.5 \mathrm{~kg}$ and $\geq 0.5 \mathrm{~cm}$, respectively. The mean of the two nearest measures was used. Growth velocity during the first year was determined from differences between weight-for-age $\mathrm{z}$-scores (WAZ; using WHO standards) (20) at 12 months and at birth. Differences $>0.67$ sD were considered to indicate accelerated growth or rapid weight gain $(\mathrm{RWG})^{(21)}$. BMI (weight $(\mathrm{kg}) /$ height $(\mathrm{m})^{2}$ ) at the age of 2 years was calculated based on measured weight and height data. Overweight/obesity status was determined both according to the age- and sex-specific cut-offs for BMI established by the International Obesity Task Force (IOTF) ${ }^{(22)}$ and according to WHO Child Growth Standards (using BMI-for-age $\mathrm{z}$-score $>2$ ) ${ }^{(20)}$.

\section{Covariates}

Our analyses considered various perinatal and developmental risk factors potentially related to infant feeding practices, accelerated infant growth and childhood overweight/ obesity. These include maternal smoking during pregnancy, gestational diabetes, prepregnancy overweight/ obesity status (BMI $\geq 25$, derived from reported weight before pregnancy and height measured at first prenatal 


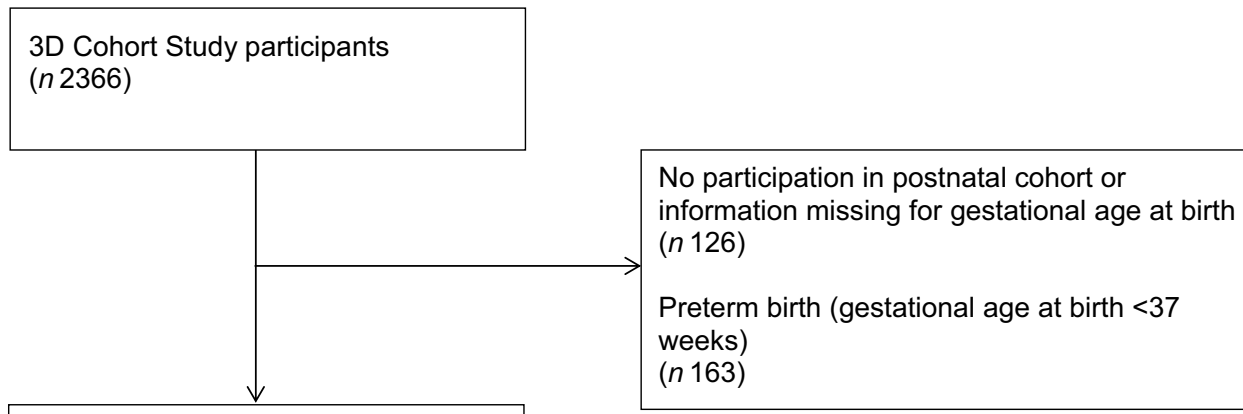

Term infants in postnatal cohort (n 2077)
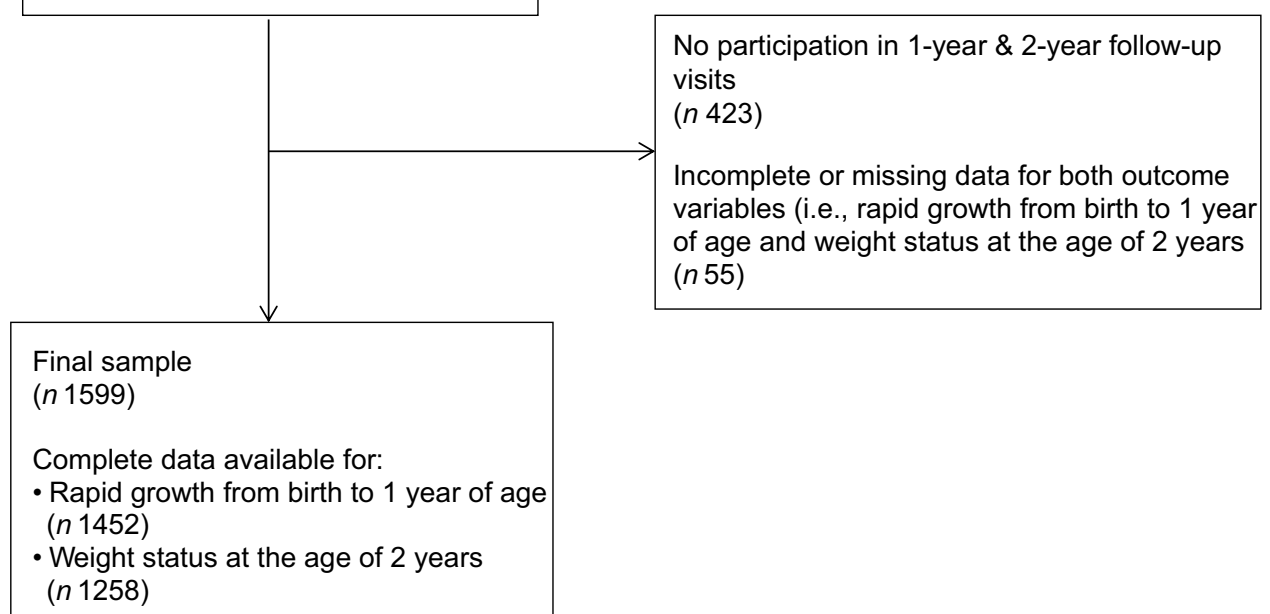

Fig. 1 Flow chart of 3D Cohort Study participants included in analyses

visit), mode of delivery, parity, mother's age at first prenatal visit, immigrant status (derived from reported birthplace), and education attainment (highest level reported at first prenatal visit), and annual household income. Other covariates pertaining to children include infant sex, gestational age at birth and birth weight.

\section{Statistical analyses}

Sociodemographic and anthropometric characteristics of children in the first 2 years of life were summarised using descriptive statistics, including mean and standard deviation, frequencies and percentages. Associations between categorical variables were assessed using univariate logistic regression. Multivariable logistic regressions were used to examine the association between breastfeeding practices and rapid growth in the first year of life, while also considering other important early-life risk factors, and to explore predictors of overweight/obesity status at the age of 2 years. Multicollinearity among covariates was evaluated using a generalised variance inflation factor $^{(23)}$. To select a parsimonious model, we examined the univariable association between each risk factor and the outcome. Variables where the $P$-value was $<0 \cdot 2$, based on the likelihood ratio test, were selected for consideration in building the final model. Model selection was then carried out to minimise Akaike information criterion in a stepwise manner. All variables were tested for significant interactions. We also examined missing data patterns. In our primary analyses, individuals for whom selected covariate data were missing were removed before regression analysis. We also performed a sensitivity analysis, which allowed imputing missing values to covariates using an iterative imputation method (missForest) ${ }^{(24-26)}$. The associations between risk factors and outcomes of interest in the final models were reported as adjusted OR with $95 \% \mathrm{CI}$ and associated $P$-values. The significance level was set at 0.05. All the analyses were performed using $\mathrm{R}$ Statistical Software 3.5.0 $0^{(27)}$.

\section{Results}

Table 1 presents anthropometric characteristics of the participants ( $n$ 1599) over the first 2 years of life. Mean and standard deviation for birth weight were $3430 \mathrm{~g}$ (435); few children had birth weights lower than $2500 \mathrm{~g}$ ( $1 \%$ of the sample), whereas $9 \%$ had birth weights greater than $4000 \mathrm{~g}$. More than a quarter (28\%) of the sample 
Table 1 Anthropometric characteristics of children in the first 2 years of life ( $n$ 1599)

\begin{tabular}{|c|c|c|c|c|c|}
\hline & $n$ & Mean & SD & $\%$ & $95 \% \mathrm{Cl}$ \\
\hline \multicolumn{6}{|l|}{ Birth } \\
\hline Gestational age (weeks)* & 1599 & $39 \cdot 2$ & 1.1 & & \\
\hline Weight $(\mathrm{g}) \dagger$ & 1599 & 3430 & 435 & & \\
\hline Length $(\mathrm{cm})$ & 1456 & 51.3 & 2.4 & & \\
\hline \multicolumn{6}{|l|}{ Postnatal visit - age 1 yearł } \\
\hline Age (years) & 1452 & $1 \cdot 0$ & 0.06 & & \\
\hline Weight $(\mathrm{kg})$ & 1452 & $9 \cdot 8$ & $1 \cdot 1$ & & \\
\hline Length $(\mathrm{cm})$ & 1446 & $75 \cdot 3$ & $2 \cdot 8$ & & \\
\hline WAZ§ & 1452 & 0.33 & 0.95 & & \\
\hline \multicolumn{6}{|l|}{ RWG - birth to 1 yearll } \\
\hline No & 1049 & & & $72 \cdot 2$ & $69 \cdot 9,74.5$ \\
\hline Yes & 403 & & & $27 \cdot 8$ & $25 \cdot 5,30 \cdot 1$ \\
\hline \multicolumn{6}{|c|}{ Postnatal visit - age 2 years? } \\
\hline Age (years) & 1258 & $2 \cdot 1$ & 0.18 & & \\
\hline Weight $(\mathrm{kg})$ & 1258 & $12 \cdot 6$ & 1.5 & & \\
\hline Height (cm) & 1258 & $87 \cdot 1$ & 3.7 & & \\
\hline $\mathrm{BMI}^{* *} \mathrm{~m}$ & 1258 & $16 \cdot 5$ & $1 \cdot 3$ & & \\
\hline BMI z-score§ & 1258 & 0.53 & 0.97 & & \\
\hline \multicolumn{6}{|c|}{ Overweight or obese - IOTF criteria†† } \\
\hline No & 1142 & & & $90 \cdot 8$ & $89 \cdot 0,92 \cdot 3$ \\
\hline Yes & 116 & & & $9 \cdot 2$ & $7 \cdot 7,10 \cdot 9$ \\
\hline \multicolumn{6}{|c|}{ Overweight or obese - WHO definitionłł } \\
\hline No & 1190 & & & 94.6 & $93 \cdot 2,95 \cdot 7$ \\
\hline Yes & 68 & & & 5.4 & $4 \cdot 3,6 \cdot 8$ \\
\hline
\end{tabular}

WAZ, weight-for-age z-score; RWG, rapid weight gain; IOTF, International Obesity Task Force.

${ }^{*}$ Term infants ( $\geq 37$ weeks).

†Low birth weight $(<2500 \mathrm{~g}), n 17$ (1.1\%); high birth weight (> $4000 \mathrm{~g}), n 145(9.1 \%)$.

$\ddagger$ Children with complete data for the rate of growth between birth and 1 year of age $(n 1452)$.

$\S$ According to WHO Child Growth Standards ${ }^{(20)}$.

IIDifference in WAZ (birth to 1 year of age) above 0.67.

ๆChildren with complete data for overweight/obesity status at the age of 2 years $(n 1258)$.

${ }^{\star *}$ Weight $(\mathrm{kg}) /$ height $(\mathrm{m})^{2}$.

††Age- and sex-specific cut-offs for BMI(22).

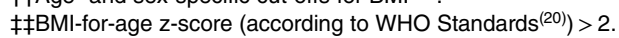

showed RWG in their first year of life, although less than one child in ten was overweight or obese at the age of 2 years $(9 \%$ according to IOTF criteria; $5 \%$ according to the WHO definition).

Table 2 presents other characteristics of the study sample, including infant feeding practices. Almost all children in the study were breastfed at least once; only $3.3 \%$ were never breastfed. A majority of the children were breastfed for 6 months or more ( $69 \%$ ) and about half of those $34 \%$ of the sample) were breastfed throughout the first year. Nevertheless, exclusive breast-feeding for 6 months, as recommended by $\mathrm{WHO}$, was reported for only about $17 \%$ of the children. Overall, longer durations of exclusive breastfeeding were associated with total breast-feeding that continued beyond the first year $(P<0.05$, data not shown). Both total and exclusive breast-feeding durations were negatively associated with RWG in the first year $(P<0.001)$. We did not, however, detect any association between breast-feeding duration (whether total or exclusive) and overweight/obesity status at the age of 2 years (whether based on IOTF or WHO definitions).

No multicollinearity among the covariates was identified. We also examined interactions among covariates; none was significant and thus not presented. Based on multivariable logistic regression analyses, breast-feeding appears to be an important and independent protective factor for rapid growth in infancy (Table 3). After controlling for selected covariates, children breastfed for less than 6 months, and those breastfed from 6 months up to a year were 2.5 times (OR 2.45; $95 \%$ CI 1.76, 3.41) and 1.8 times (OR 1.78 ; $95 \%$ CI 1.29, 2.45) more likely, respectively, to show RWG up to 12 months compared with children breastfed for at least 1 year. Similarly, those who were exclusively breastfed for less than 3 months had significantly greater odds of RWG in the first year (OR 1.94 to 1.96; $95 \%$ CI $1.25,3.04)$ compared with children exclusively breastfed for 6 months (as recommended). Considering total and exclusive breast-feeding practices together, the odds of having accelerated growth throughout the first year were 2.5 times greater (OR 2.50; $95 \%$ CI 1.57, 4.11) among children breastfed less than 1 year and exclusively breastfed for less than 6 months, compared with children fed in accordance with breast-feeding recommendations.

Other independent predictors of RWG in the first year were lower gestational age at birth $(<39$ weeks compared to $\geq 39$ weeks; e.g. OR 2.64; $95 \%$ CI 2.02, 3.46 in Model I); younger maternal age (19-24 years compared to 25-34 years; e.g. OR 1.75; $95 \%$ CI 1.07, 2.83 in Model I); maternal immigrant status (relative to being born in Canada; e.g. OR 1.54; $95 \%$ CI 1.16, 2.05 in Model I) and maternal 
Table 2 Rapid weight gain in the first year and overweight/obesity status at the age of 2 years by selected characteristics*

\begin{tabular}{|c|c|c|c|c|c|c|c|c|}
\hline & \multicolumn{2}{|c|}{$\begin{array}{l}\text { Study sample } \\
(n \text { 1599) }\end{array}$} & \multicolumn{2}{|c|}{$\begin{array}{c}\text { RWG from birth to } \\
1 \text { year of aget }\end{array}$} & \multicolumn{2}{|c|}{$\begin{array}{l}\text { Overweight/obese } \\
\text { at the age of } 2 \\
\text { years (IOTF) } \ddagger, \S\end{array}$} & \multicolumn{2}{|c|}{$\begin{array}{l}\text { Overweight/obese } \\
\text { at the age of } 2 \\
\text { years (WHO) } \pm, \|\end{array}$} \\
\hline & $n$ & $\%$ & $\%$ & $P$-value & $\%$ & $P$-value & $\%$ & $P$-value \\
\hline Maternal ageף & & & & 0.008 & & 0.334 & & 0.992 \\
\hline $19-24$ years & 98 & $6 \cdot 1$ & 41.6 & & $14 \cdot 1$ & & $5 \cdot 6$ & \\
\hline $25-34$ years & 1158 & $72 \cdot 6$ & $26 \cdot 3$ & & $8 \cdot 8$ & & 5.5 & \\
\hline$\geq 35$ years & 339 & $21 \cdot 3$ & $28 \cdot 8$ & & $9 \cdot 0$ & & $5 \cdot 6$ & \\
\hline Missing & 4 & - & & & & & & \\
\hline Maternal education & & & & 0.756 & & 0.298 & & 0.374 \\
\hline Secondary school diploma or less & 117 & 7.4 & $26 \cdot 0$ & & $12 \cdot 9$ & & $8 \cdot 2$ & \\
\hline Higher than secondary school diploma & 1471 & $92 \cdot 6$ & $27 \cdot 9$ & & 8.9 & & $5 \cdot 3$ & \\
\hline Missing & 11 & - & & & & & & \\
\hline Household income (CAD) & & & & 0.046 & & 0.123 & & 0.407 \\
\hline$<\$ 60000$ & 420 & $27 \cdot 4$ & 31.6 & & 11.5 & & $6 \cdot 7$ & \\
\hline$\geq \$ 60000$ & 1114 & $72 \cdot 6$ & $25 \cdot 9$ & & 8.3 & & $5 \cdot 2$ & \\
\hline $\bar{M}$ issing & 65 & - & & & & & & \\
\hline Mother's immigrant status & & & & 0.031 & & 0.235 & & 0.500 \\
\hline Non-immigrant & 1114 & $69 \cdot 8$ & $26 \cdot 2$ & & 8.6 & & $5 \cdot 2$ & \\
\hline Immigrant & 483 & $30 \cdot 2$ & $32 \cdot 0$ & & $11 \cdot 0$ & & $6 \cdot 3$ & \\
\hline Missing & 2 & - & & & & & & \\
\hline Parity & & & & $<0.001$ & & 0.677 & & 0.738 \\
\hline 0 & 881 & $55 \cdot 1$ & 31.6 & & $8 \cdot 8$ & & $5 \cdot 2$ & \\
\hline $1+$ & 718 & 44.9 & 22.9 & & $9 \cdot 7$ & & $5 \cdot 8$ & \\
\hline Mode of delivery & & & & 0.769 & & 0.028 & & 0.039 \\
\hline Vaginal & 1187 & $74 \cdot 3$ & 27.5 & & $8 \cdot 1$ & & 4.6 & \\
\hline Cesarean & 410 & $25 \cdot 7$ & 28.5 & & $12 \cdot 4$ & & 7.9 & \\
\hline Missing & 2 & - & & & & & & \\
\hline Maternal smoking during pregnancy & & & & 0.156 & & 0.750 & & 1.000 \\
\hline No & 1389 & $87 \cdot 1$ & $27 \cdot 1$ & & $9 \cdot 1$ & & $5 \cdot 5$ & \\
\hline Yes & 206 & 12.9 & 32.4 & & $10 \cdot 3$ & & $5 \cdot 8$ & \\
\hline Missing & 4 & - & & & & & & \\
\hline Gestational diabetes & & & & 0.157 & & 0.672 & & 0.139 \\
\hline No & 1448 & $90 \cdot 8$ & $27 \cdot 1$ & & $9 \cdot 1$ & & $5 \cdot 2$ & \\
\hline Yes & 147 & $9 \cdot 2$ & $33 \cdot 3$ & & $10 \cdot 8$ & & $9 \cdot 0$ & \\
\hline Missing & 4 & - & & & & & & \\
\hline Overweight/obese before pregnancy** & & & & 0.069 & & 0.001 & & 0.015 \\
\hline No & 1061 & $70 \cdot 2$ & $26 \cdot 3$ & & 7.4 & & 4.4 & \\
\hline Yes & 451 & $29 \cdot 8$ & $31 \cdot 3$ & & $13 \cdot 4$ & & $8 \cdot 0$ & \\
\hline Missing & 87 & - & & & & & & \\
\hline Infant sex & & & & 0.221 & & 0.580 & & 0.082 \\
\hline Boy & 801 & $50 \cdot 1$ & $26 \cdot 2$ & & $9 \cdot 7$ & & $6 \cdot 6$ & \\
\hline Girl & 798 & 49.9 & $29 \cdot 3$ & & $8 \cdot 7$ & & $4 \cdot 3$ & \\
\hline Gestational age at birth & & & & $<0.001$ & & 0.938 & & 0.469 \\
\hline $37-<39$ weeks & 423 & $26 \cdot 5$ & $43 \cdot 3$ & & 9.5 & & $6 \cdot 4$ & \\
\hline$\geq 39$ weeks & 1176 & 73.5 & $22 \cdot 4$ & & $9 \cdot 1$ & & $5 \cdot 2$ & \\
\hline Birth weight & & & & $<0.001$ & & 0.001 & & 0.003 \\
\hline$\leq 4000 \mathrm{~g}$ & 1454 & 90.9 & $29 \cdot 6$ & & $8 \cdot 3$ & & $4 \cdot 8$ & \\
\hline$>4000 \mathrm{~g}$ & 145 & $9 \cdot 1$ & $9 \cdot 8$ & & $17 \cdot 8$ & & 11.9 & \\
\hline Total breast-feeding duration & & & & $<0.001$ & & 0.778 & & 0.319 \\
\hline$<6$ months (incl. no breast-feeding††) & 468 & 31.0 & $36 \cdot 5$ & & $9 \cdot 7$ & & $5 \cdot 6$ & \\
\hline $6-<12$ months & 530 & $35 \cdot 1$ & $28 \cdot 2$ & & 9.5 & & $6 \cdot 6$ & \\
\hline$\geq 12$ months & 511 & 33.9 & $19 \cdot 7$ & & $8 \cdot 3$ & & 4.2 & \\
\hline Missing & 90 & - & & & & & & \\
\hline Exclusive breast-feeding duration & & & & $<0.001$ & & 0.362 & & 0.432 \\
\hline$<1$ month (incl. no breast-feeding) & 572 & 37.4 & 34.7 & & 9.4 & & $5 \cdot 6$ & \\
\hline $1-<3$ months & 260 & $17 \cdot 0$ & $31 \cdot 0$ & & $12 \cdot 0$ & & $7 \cdot 7$ & \\
\hline $3-<6$ months & 445 & $29 \cdot 1$ & $22 \cdot 1$ & & 7.6 & & 4.4 & \\
\hline$\geq 6$ months & 252 & $16 \cdot 5$ & $20 \cdot 3$ & & 8.5 & & $5 \cdot 3$ & \\
\hline Missing & 70 & & & & & & & \\
\hline
\end{tabular}

RWG, rapid weight gain; IOTF, International Obesity Task Force; CAD, Canadian Dollar.

*Based on univariate logistic regression.

tChildren with complete data for rate of growth between birth and age 1 ( $n$ 1452).

$\ddagger$ Children with complete data for overweight/obesity status at age 2 ( $n$ 1258).

$\S$ Age- and sex-specific cut-offs for BMI (22).

IIBMI-for-age $\mathrm{z}$-score (according to WHO Standards $\left.{ }^{(20)}\right)>2$

qMean (SD): 31.5 (4.4).

${ }^{\star *} \mathrm{BMI} \geq 25$, derived from reported weight before pregnancy and height measured at the first prenatal visit.

††No breast-feeding, $n 50$ (3.3\%). 
Table $3 \mathrm{OR}$ and $95 \% \mathrm{Cl}$ for rapid weight gain in first year by breast-feeding practices and significant covariates*

\begin{tabular}{|c|c|c|c|c|}
\hline & & OR & $95 \% \mathrm{Cl}$ & $P$-value \\
\hline \multicolumn{5}{|c|}{ Model I: RWG in the first year as the outcome and total breast-feeding duration as the key exposure $(n 1369)$} \\
\hline (Intercept) & & 0.17 & $0.12,0.23$ & $<0.001$ \\
\hline \multirow[t]{3}{*}{ Total breast-feeding duration } & $\geq 12$ months & 1.00 & - & \\
\hline & $\overline{6}$ months $-<12$ months & 1.78 & $1 \cdot 29,2.45$ & $<0.001$ \\
\hline & $<6$ months & 2.45 & $1.76,3.41$ & $<0.001$ \\
\hline \multirow[t]{2}{*}{ Overweight/obese before pregnancy† } & No & 1.00 & - & \\
\hline & Yes & 1.34 & $1.02,1.76$ & 0.034 \\
\hline \multirow[t]{2}{*}{ Parity } & 0 & 1.00 & - & \\
\hline & $1+$ & 0.61 & $0.47,0.79$ & $<0.001$ \\
\hline \multirow[t]{3}{*}{ Maternal age } & 25-34 years & 1.00 & - & \\
\hline & $19-24$ years & 1.75 & $1 \cdot 07,2 \cdot 83$ & 0.024 \\
\hline & $\geq 35$ years & 1.23 & $0.90,1.68$ & 0.195 \\
\hline \multirow[t]{2}{*}{ Mother's immigrant status } & $\bar{N}$ on-immigrant & 1.00 & - & \\
\hline & Immigrant & 1.54 & $1 \cdot 16,2 \cdot 05$ & 0.003 \\
\hline \multirow[t]{2}{*}{ Gestational age at birth } & $\geq 39$ weeks & 1.00 & - & \\
\hline & $37-<39$ weeks & $2 \cdot 64$ & $2 \cdot 02,3.46$ & $<0.001$ \\
\hline \multirow[t]{2}{*}{ Birth weight } & $\leq 4000 \mathrm{~g}$ & 1.00 & - & \\
\hline & $>4000 \mathrm{~g}$ & 0.32 & $0.17,0.56$ & $<0.001$ \\
\hline \multicolumn{5}{|c|}{ Model II: RWG in the first year as the outcome and exclusive breast-feeding duration as the key exposure $(n 1366)$} \\
\hline (Intercept) & & 0.19 & $0.13,0.28$ & $<0.001$ \\
\hline \multirow[t]{4}{*}{ Exclusive breast-feeding duration } & $\geq 6$ months & 1.00 & - & \\
\hline & $\overline{3}-<6$ months & 1.23 & $0.82,1.87$ & 0.324 \\
\hline & $1-<3$ months & 1.94 & $1.25,3.04$ & 0.004 \\
\hline & $<1$ month (or no breast-feeding) & 1.96 & $1.33,2.90$ & 0.001 \\
\hline \multirow[t]{2}{*}{ Overweight/obese before pregnancy† } & No $\quad$ (n) & 1.00 & - & \\
\hline & Yes & 1.38 & $1.05,1.81$ & 0.021 \\
\hline \multirow[t]{2}{*}{ Parity } & 0 & 1.00 & - & \\
\hline & $1+\quad$ & 0.62 & $0.47,0.80$ & $<0.001$ \\
\hline \multirow[t]{3}{*}{ Maternal age } & $25-34$ years & 1.00 & - & \\
\hline & 19-24 years & 1.79 & $1 \cdot 10,2 \cdot 90$ & 0.018 \\
\hline & $\geq 35$ years & 1.15 & $0.84,1.56$ & 0.392 \\
\hline \multirow[t]{2}{*}{ Mother's immigrant status } & $\bar{N}$ on-immigrant & 1.00 & - & \\
\hline & Immigrant & 1.36 & $1.03,1.79$ & 0.031 \\
\hline \multirow[t]{2}{*}{ Gestational age at birth } & $\geq 39$ weeks & 1.00 & - & \\
\hline & $37-<39$ weeks & 2.56 & $1.96,3.35$ & $<0.001$ \\
\hline \multirow[t]{2}{*}{ Birth weight } & $\leq 4000 \mathrm{~g}$ & 1.00 & - & \\
\hline & $>4000 \mathrm{~g}$ & 0.31 & $0.16,0.55$ & $<0.001$ \\
\hline \multicolumn{5}{|c|}{ Model III: RWG in the first year as the outcome and a combination of breast-feeding durations as the key exposure $(n 1365)$} \\
\hline (Intercept) & & 0.15 & $0.09,0.24$ & $<0.001$ \\
\hline \multirow[t]{4}{*}{ Combination of breast-feeding durations } & $\geq 12$ months total $\& \geq 6$ months exclusive & 1.00 & - & \\
\hline & $\geq 12$ months total \& $<6$ months exclusive & 1.23 & $0.73,2.11$ & 0.447 \\
\hline & $<12$ months total $\& \geq 6$ months exclusive & 1.58 & $0.80,3.09$ & 0.181 \\
\hline & $<12$ months total $\&<6$ months exclusive & 2.50 & $1.57,4.11$ & $<0.001$ \\
\hline Overweight/obese before pregnancy† & No & 1.00 & - & \\
\hline & Yes & $1 \cdot 38$ & $1 \cdot 05,1 \cdot 81$ & 0.021 \\
\hline Parity & 0 & 1.00 & - & \\
\hline & $1+$ & 0.61 & $0.47,0.79$ & $<0.001$ \\
\hline Maternal age & 25-34 years & 1.00 & - & \\
\hline & $19-24$ years & 1.72 & $1.05,2.79$ & 0.029 \\
\hline & $\geq 35$ years & $1 \cdot 24$ & $0.90,1.69$ & 0.188 \\
\hline Mother's immigrant status & $\bar{N}$ on-immigrant & 1.00 & - & \\
\hline & Immigrant & 1.55 & $1 \cdot 17,2 \cdot 06$ & 0.003 \\
\hline Gestational age at birth & $\geq 39$ weeks & 1.00 & - & \\
\hline & $37-<39$ weeks & 2.66 & $2.03,3.49$ & $<0.001$ \\
\hline Birth weight & $\leq 4000 \mathrm{~g}$ & 1.00 & - & \\
\hline & $>4000 \mathrm{~g}$ & 0.32 & $0.16,0.56$ & $<0.001$ \\
\hline
\end{tabular}

RWG, rapid weight gain; AIC, Akaike information criterion.

*Covariates considered in the multivariable logistic regression analyses: maternal age, maternal education, household income, mother's immigrant status, parity, mode of delivery, maternal smoking during pregnancy, gestational diabetes, overweight status before pregnancy, infant sex, gestational age at birth and birth weight. In order to select a parsimonious model, we examined the univariable association between each risk factor and the outcome. Variables where the $P$-value was $<0 \cdot 2$, based on the likelihood ratio test, were selected for consideration in building the final model. Model selection was then carried out to minimise AIC in a stepwise manner. All variables were tested for significant interactions; none were significant. Individuals with incomplete values for selected covariates were removed before undertaking regression analyses. $\dagger \mathrm{BMI} \geq 25$, derived from reported weight before pregnancy and height measured at the first prenatal visit.

overweight/obesity before pregnancy (relative to not having excess weight; e.g. OR 1.34; $95 \%$ CI 1.02, 1.76 in Model I). Conversely, children born with high birth weights (> 4000 g relative to others; e.g. OR 0.32; $95 \%$ CI $0 \cdot 17$,
0.56 in Model I) and those who were not first-born children (relative to infants of primiparous mothers; e.g. OR 0.61; $95 \%$ CI $0.47,0.79$ in Model I) appeared to be less prone to RWG in the first year. 
Table 4 OR and $95 \% \mathrm{Cl}$ for overweight/obesity at the age of 2 years (IOTF criteria) by rapid weight gain and significant covariates $(n 1047)^{*}$

\begin{tabular}{|c|c|c|c|c|}
\hline Characteristics & & OR & $95 \% \mathrm{Cl}$ & $P$-value \\
\hline (Intercept) & & 0.06 & $0.03,0.13$ & $<0.001$ \\
\hline \multirow[t]{2}{*}{ RWG in the first year of life } & No & 1.00 & & \\
\hline & Yes & $6 \cdot 98$ & $4 \cdot 35,11 \cdot 47$ & $<0.001$ \\
\hline \multirow[t]{2}{*}{ Overweight/obese before pregnancy $\dagger$} & No & 1.00 & - & \\
\hline & Yes & $1 \cdot 80$ & $1 \cdot 14,2 \cdot 82$ & 0.011 \\
\hline \multirow[t]{2}{*}{ Maternal education: Secondary school diploma or less } & No & 1.00 & - & \\
\hline & Yes & $2 \cdot 33$ & $1 \cdot 03,5 \cdot 00$ & 0.032 \\
\hline \multirow[t]{2}{*}{ Birth weight } & $\leq 4000 \mathrm{~g}$ & 1.00 & $-\bar{s} 00$ & \\
\hline & $>4000 \mathrm{~g}$ & 4.71 & $2 \cdot 46,8 \cdot 85$ & $<0.001$ \\
\hline
\end{tabular}

IOTF, International Obesity Task Force; RWG, rapid weight gain; AIC, Akaike information criterion.

${ }^{*}$ Covariates considered in the multivariable logistic regression analyses: breast-feeding variables, maternal age, maternal education, household income, mother's immigrant status, parity, mode of delivery, maternal smoking during pregnancy, gestational diabetes, overweight status before pregnancy, infant sex, gestational age at birth and birth weight. In order to select a parsimonious model, we examined the univariable association between each risk factor and the outcome. Variables where the $P$-value was $<0.2$, based on the likelihood ratio test, were selected for consideration in building the final model. Model selection was then carried out to minimise AIC in a stepwise manner. All variables were tested for significant interactions; none were significant. Individuals with incomplete values for selected covariates were removed before undertaking regression analyses.

$\dagger B M I \geq 25$, derived from reported weight before pregnancy and height measured at the first prenatal visit.

As shown in Table 4, accelerated growth in the first year of life appears to be a major independent predictor of overweight or obesity at the age of 2 years (based on IOTF criteria). Similar results related to overweight/obesity status based on the WHO definition are presented in Supplemental Table 2. For children showing RWG between birth and 1 year, the odds of having excess weight by the age of 2 years were seven times greater than that of other children (OR 6.98; $95 \%$ CI 4.35, 11.47). Similarly, children born with high birth weights (relative to others; OR 4.71; $95 \%$ CI $2 \cdot 46,8 \cdot 85$ ), and those born to overweight or obese mothers (relative to others; OR 1.80; $95 \%$ CI 1.14, 2.82), or to mothers who had earned a secondary school diploma or less (OR 2.33; $95 \%$ CI 1.03, 5.00) had greater odds of being overweight or obese at the age of 2 years (based on IOTF criteria). However, overweight/obesity status before pregnancy and level of maternal education are not significantly associated with overweight/obesity at the age of 2 years under the WHO definition.

Concerning the sensitivity analysis, none of the databased model fits deviated substantially, after imputing missing values to the covariates, from results based on complete-case analyses, as indicated by the results presented in Supplemental Tables 3 and 4.

\section{Discussion}

The present study assesses associations between various early-life factors and excess weight at the age of 2 years among children in the 3D Cohort, with particular emphasis on breast-feeding and growth rates in the first year. Upon analysing an extensive array of maternal and infant characteristics, we noted that major predictors of excess weight during the first $1000 \mathrm{~d}$ were (in decreasing order of importance) RWG in the first year of life and high birth weight (based on IOTF and WHO definitions of overweight/ obesity at the age of 2 years), and low maternal educational attainment and maternal overweight or obesity before pregnancy (based on IOTF definition of overweight/ obesity at the age of 2 years). We did not detect any direct independent associations between total and exclusive breast-feeding durations and overweight/obesity status at the age of 2 years. Nevertheless, breast-feeding exclusively for 6 months as recommended (compared to $<3$ months) and prolonged total breast-feeding for at least 12 months (compared to $<12$ months) were inversely associated with RWG in the first year.

Few large-scale longitudinal studies have examined whether compliance with current breast-feeding recommendations (i.e. prolonged total breast-feeding and exclusive breast-feeding for 6 months) confers weight-status advantages by the age of 2 years, while also considering other early-life factors, particularly rapid growth in infancy. As for prolonged breast-feeding, a longitudinal study ( $n$ 878) conducted in Australia found that children who were breastfed for at least 12 months had lower odds of being overweight or obese at 29 months (mean age) compared to children breastfed for less than 17 weeks or not at all (OR 0.49; $95 \%$ CI 0.27, 0.90) ${ }^{(28)}$. Similarly, a German cohort study ( $n$ 855) found that exclusive breast-feeding for at least 6 months (compared with less than 3 months; OR $0.40 ; 95 \% \mathrm{CI} 0 \cdot 20,0 \cdot 90$ ) had a protective effect on overweight and obesity at the age of 2 years ${ }^{(29)}$. Both studies included adjustments for a number of prenatal factors and maternal characteristics, but neither considered infancy growth rates. Our findings, however, are in agreement with the results of two other large-scale cohort studies that found no association between breast-feeding duration and overweight ${ }^{(30,31)}$ or risk of overweight ${ }^{(31)}$ at the age of 2 years. Interestingly, both prospective studies (conducted in the Netherlands) reported an association between longer 
breast-feeding duration and slower growth in infancy (relative to absolute weight gain in the first year ${ }^{(30)}$ and growth rates between 3 and 6 months of age $\left.{ }^{(31)}\right)$.

In the last two decades, an extensive literature has explored the relation between breast-feeding and excess weight later in life ${ }^{(12-18)}$. However, heterogeneity in study design, outcome measures and exposure definition may have contributed to inconsistent results ${ }^{(11,13,15)}$. When considering the methodological aspects of published studies, weaker associations were observed in larger-scale longitudinal studies and in those incorporating more extensive adjustments for potential confounders, particularly socioeconomic factors, birth weight, gestational age and parental weight status ${ }^{(13)}$. Such characteristics could apply to the present study, which may partly explain why we did not detect significant associations. Inadequate statistical power, however, cannot be excluded, considering the relatively low prevalence $(<10 \%)$ at the age of 2 years of overweight/obesity in our sample.

The association between accelerated growth in infancy and overweight or obesity later in life is, by contrast, well established $^{(5-7,32)}$. Indeed, we found RWG in the first year of life to be the main predictor of excess weight at the age of 2 years. Following up on patterns of growth in infancy in order to monitor, and ideally to prevent, accelerated growth remains an important strategy in early-life interventions designed to promote a healthy weight later in life. This strategy is especially relevant considering that BMI at the age of 2 years has been found to be a predictor of BMI at the age of 8 years ${ }^{(33)}$. By the end of the first year of life, the propensity for excess weight may, in fact, already be determined for the most part ${ }^{(34,35)}$.

The notion that breast-feeding might be a modifiable factor that contributes to healthy growth during infancy is also widely accepted. Indeed, WHO Child Growth Standards are based on the growth patterns of breastfed children, which served as normative models of growth ${ }^{(20)}$. Compared to formula-fed infants, breastfed infants tend to have, overall, slower growth trajectories up to the age of 1 year $^{(36,37)}$. By extension, our findings are consistent with those of other studies reporting that shorter-duration breast-feeding and, conversely, earlier introduction of commercial infant formula were associated with increased growth rates in infancy ${ }^{(31,38,39)}$. Nevertheless, because feeding practices and infant growth patterns might mutually influence each other over time, our research results may be correlational rather than causal. Indeed, some researchers have proposed a 'reverse causality' hypothesis ${ }^{(40,41)}$, whereby a child who is growing too fast might be more likely to show signs of hunger. Such an outcome could actually accelerate the weaning process or lead to the discontinuation of exclusive breast-feeding.

Investigating potential reverse causality requires that anthropometric measurements precede changes in breast-feeding status ${ }^{(40)}$. Based on the model that Kramer et al. (2011) $)^{(40)}$ employed in a much larger study
( $n 17$ 046), we carried out exploratory analyses of children who participated in the 3D Cohort Study, who were still being breastfed at 3 months, and for whom complete data were available for computing WAZ (based on WHO standards) at the time of the 3-month follow-up visit. We determined infant size at the age of 3 months according to three categories: small (WAZ $<-1$ ), normal (WAZ $=-1$ to 1) and large (WAZ $>1$ ). We also measured RWG between birth and 3 months (based on criteria described in the method section for the first year). No significant association between infant size at 3 months and weaning after 3 months, up to 6 months, was found (data not shown). At 6 months, however, discontinuity in exclusive breastfeeding was higher among smaller infants compared to larger babies $\left(72 \% v .53 \% ; P=0.028\right.$, based on $\chi^{2}$ tests of association). This last result is consistent with observations made by Kramer et al. (2011) ${ }^{(40)}$. It suggests that mothers of smaller infants may perceive that their child is not growing properly and that maternal milk alone will not be sufficient to meet nutritional needs, thus predisposing to earlier introduction of formula or other complementary foods. In other words, in this case, patterns of growth may have determined exclusive breast-feeding duration. Still, we did not detect an association between RWG in the first 3 months and weaning (or discontinuity of exclusive breast-feeding) after 3 months, up to 6 months. Altogether, these results support the idea that prolonged total breast-feeding, at least, may prove protective against rapid growth in the first year of life.

The other independent predictors of overweight or obesity at the age of 2 years (identified in the present study as high birth weight, low maternal educational attainment, and maternal overweight or obesity) have been recognised in various reviews and meta-analyses as key risk factors for childhood obesity ${ }^{(32,42,43)}$. We found that children born with high birth weights ( $>4000 \mathrm{~g}$ ) were not likely to manifest RWG in the first year, yet were nevertheless more likely to have excess weight at the age of 2 years, independent of other covariates, including gestational diabetes, gestational age at birth and maternal overweight/obesity. Although genetics may account for some of the variability in birth weight $^{(44)}$, certain modifiable determinants of intrauterine growth (e.g. prenatal nutrition, gestational weight gain) have likely played a role and thus ought to be considered in preventive interventions. Similarly, the influence that low levels of educational attainment have on overweight/obesity status among young children highlights the necessity of reducing socio-economic and health status inequalities. Finally, although genetics and in utero programming processes may partially explain the influence that excess maternal weight has on childhood overweight and obesity, shared familial environments likely also play a major role ${ }^{(45)}$. Interventions promoting healthy weight among women of childbearing age, particularly those of low socio-economic status, will remain decisive in countering intergenerational obesity cycles $^{(46)}$. Similarly, 
interventions targeting children of immigrants and of younger mothers, as well as early terms and first-born children, all of whom were found to be more prone to RWG, appear relevant.

This study relies on a longitudinal study design with a relatively large sample size. It has collected high-quality data that subsume a host of prenatal and early-life characteristics. Anthropometric data were obtained by direct measurement, based on a standardised protocol. Moreover, we used two definitions to assess overweight/obesity status at the age of 2 years. Infant feeding information was collected at two points in time during the first year of life, which minimises memory biases. The analyses took into account two key infant feeding indicators that accord with current guidelines: exclusive breast-feeding for 6 months and continued total breast-feeding ( $\geq 12$ months) ${ }^{(47)}$. We also adopted a strict definition of exclusive breast-feeding that corresponds with the WHO definition - an approach that is rarely considered in published studies.

Although residual confounding is not impossible, we have attempted to minimise it by incorporating major potential confounders in our analyses. Still, other dietary factors beyond breast-feeding may have played a role in children's growth and weight status throughout the first 2 years (e.g. consumption of sugary drinks and ultraprocessed food, consumption of vegetables and fruit). Because we did not collect detailed dietary intake information before the age of 2 years, our analyses could not take these dietary factors into account, which is a study limitation. However, age of introduction of cow's milk and of complementary foods (including cereal, fruit, vegetables, juice and meat) was assessed. In both cases, we did not detect any association with a RWG in the first year, nor with overweight status at the age of 2 years.

Attrition and missing data remain a source of concern in cohort studies; these limitations should be taken into consideration when generalising results. As for the treatment of missing data, we have recurred to the 'listwise deletion' technique, which deletes cases containing missing data in variables of relevance to the analysis being carried out, thereby avoiding potential biases in our analyses. As part of a sensitivity analysis, we also used 'missForest'(24) to impute missing values. Both methods led to similar results and identical conclusions. Finally, a majority of the mothers in our sample appear to have attained above-average educational levels and to belong to groups with higher-than-average incomes. For these reasons, our findings may not be generalisable to the Canadian population as a whole. Nevertheless, the data we have derived for breast-feeding rates and duration appear to be consistent with information presented in other large cohort studies in Canada ${ }^{(48,49)}$.

In conclusion, the present study indicates that RWG in the first year is a strong predictor for excess weight at the age of 2 years. The potential beneficial effects that breastfeeding has on rate of growth in the first year suggest that interventions promoting breast-feeding are relevant for obesity prevention early in life. The relatively low level of compliance with breast-feeding recommendations observed in the 3D Cohort Study makes these efforts even more relevant for population health.

\section{Acknowledgements}

Acknowledgements: The authors are grateful to the 3D Cohort Study participants who diligently took part in the postnatal data collection rounds, and to the 3D Cohort Study researchers and staff who ensured the integrity of data collection and coding. The authors would also like to thank Robert Sullivan for his assistance with manuscript editing. Financial support: This work was supported by the Canadian Institutes of Health Research (CIHR) (L.D., grant number MOP 133422), (W.D.F., grant number CRI 88413). CIHR had no role in the design, analysis or writing of this article. Conflict of interest: There are no conflicts of interest. Authorship: L.D. designed the current study, directed the analyses and interpretation of data, and had primary responsibility for final content. C.F. was responsible for all statistical analyses. B.B. and L.D. wrote the manuscript. Y.Y., Z.C.L., I.M. and W.D.F. contributed to study design and results interpretation. W.D.F., Z.C.L., I.M. and L.D. contributed to funding acquisition, methodology and data collection of the 3D Cohort Study. All authors made critical revisions to the text and approved the manuscript submitted for publication. Ethics of human subject participation: This study was conducted according to the guidelines laid down in the Declaration of Helsinki and all procedures involving research study participants were approved by the research ethics committee at the coordinating center at Sainte-Justine University Hospital in Montreal, as well as academic and hospital ethics committees at all participating study sites. Written informed consent was obtained from the participants (mothers consented for themselves and on behalf of their children).

\section{Supplementary material}

For supplementary material/s referred to in this article, please visit https://doi.org/10.1017/S1368980022000015

\section{References}

1. World Health Organization (2013) Essential Nutrition Actions. Improving Maternal, Newborn, Infant and Young Child Health and Nutrition. Geneva: WHO.

2. Herman DR, Taylor Baer M, Adams E et al. (2014) Life course perspective: evidence for the role of nutrition. Matern Child Health J 18, 450-461. 
3. Kumar S \& Kelly AS (2017) Review of childhood obesity: from epidemiology, etiology, and comorbidities to clinical assessment and treatment. Mayo Clin Proc 92, 251-265.

4. World Health Organization (2016) Consideration of the Evidence on Childhood Obesity for the Commission on Ending Childhood Obesity: Report of the ad hoc Working Group on Science and Evidence for Ending Childhood Obesity. Geneva: WHO.

5. Baird J, Fisher D, Lucas P et al. (2005) Being big or growing fast: systematic review of size and growth in infancy and later obesity. BMJ 331, 929.

6. Woo Baidal JA, Locks LM, Cheng ER et al. (2016) Risk factors for childhood obesity in the first 1000 Days: a systematic review. Am J Prev Med 50, 761-779.

7. Zheng M, Lamb KE, Grimes C et al. (2018) Rapid weight gain during infancy and subsequent adiposity: a systematic review and meta-analysis of evidence. Obes Rev 19, 321-332.

8. Nommsen-Rivers LA \& Dewey KG (2009) Growth of breastfed infants. Breastfeed Med 4, S45-S49.

9. Critch JN \& Canadian Paediatric Society, and Nutrition and Gastroenterology Committee (2014) Nutrition for healthy term infants, six to 24 months: an overview. Paediatr Child Health 19, 547-552.

10. Marseglia L, Manti S, D'Angelo G et al. (2015) Obesity and breastfeeding: the strength of association. Women Birth 28, 81-86.

11. Smithers LG, Kramer MS \& Lynch JW (2015) Effects of breastfeeding on obesity and intelligence: causal insights from different study designs. JAMA Pediatr 169, 707-708.

12. Horta BL, Loret de Mola C \& Victora CG (2015) Long-term consequences of breastfeeding on cholesterol, obesity, systolic blood pressure and type 2 diabetes: a systematic review and meta-analysis. Acta Paediatr 104, 30-37.

13. Horta BL \& Victora CG (2013) Long Term Effects of Breastfeeding. A Systematic Review. Geneva: WHO.

14. Qiao J, Dai LJ, Zhang Q et al. (2020) A meta-analysis of the association between breastfeeding and early childhood obesity. J Pediatr Nurs 53, 57-66.

15. Yan J, Liu L, Zhu Y et al. (2014) The association between breastfeeding and childhood obesity: a meta-analysis. BMC Public Health 14, 1267.

16. Arenz S, Rückerl R, Koletzko B et al. (2004) Breast-feeding and childhood obesity - a systematic review. Int $J$ Obes Relat Metab Disord 28, 1247-1256.

17. Owen CG, Martin RM, Whincup PH et al. (2005) Effect of infant feeding on the risk of obesity across the life course: a quantitative review of published evidence. Pediatrics 115, 1367-1377.

18. Harder T, Bergmann R, Kallischnigg G et al. (2005) Duration of breastfeeding and risk of overweight: a meta-analysis. Am J Epidemiol 162, 397-403.

19. Fraser WD, Shapiro GD, Audibert F et al. (2016) 3D cohort study: the integrated research network in perinatology of Quebec and Eastern Ontario. Paediatr Perinat Epidemiol 30, 623-632.

20. World Health Organization \& WHO Multicentre Growth Reference Study Group (2006) WHO Child Growth Standards: Length/Height-for-Age, Weight-for-Age, Weightfor-Length, Weight-for-Height and Body Mass Index-forAge - Methods and Development. Geneva: WHO.

21. Ong KK \& Loos RJ (2006) Rapid infancy weight gain and subsequent obesity: systematic reviews and hopeful suggestions. Acta Paediatr 95, 904-908.

22. Cole TJ \& Lobstein T (2012) Extended international (IOTF) body mass index cut-offs for thinness, overweight and obesity. Pediatr Obes 7, 284-294.

23. Fox J \& Monette G (1992) Generalized collinearity diagnostics. J Am Stat Assoc 87, 178-183.
24. Stekhoven DJ \& Buhlmann P (2012) MissForest - nonparametric missing value imputation for mixed-type data. Bioinf 28, 112-118.

25. Shah AD, Bartlett JW, Carpenter J et al. (2014) Comparison of random forest and parametric imputation models for imputing missing data using MICE: a CALIBER study. $A m J$ Epidemiol 179, 764-774.

26. Waljee AK, Mukherjee A, Singal AG et al. (2013) Comparison of imputation methods for missing laboratory data in medicine. BMJ Open 3, e002847.

27. R Development Core Team (2019) $R$ : A Language and Environment for Statistical Computing. Vienna, Austria: R Foundation for Statistical Computing.

28. Bell S, Yew SSY, Devenish G et al. (2018) Duration of breastfeeding, but not timing of solid food, reduces the risk of overweight and obesity in children aged 24 to 36 months: findings from an Australian cohort study. Int J Environ Res Public Health 15, 599.

29. Weyermann M, Rothenbacher D \& Brenner H (2006) Duration of breastfeeding and risk of overweight in childhood: a prospective birth cohort study from Germany. Int $J$ Obes 30, 1281-1287.

30. Gubbels JS, Thijs C, Stafleu A et al. (2011) Association of breast-feeding and feeding on demand with child weight status up to 4 years. Int J Pediatr Obes 6, e515-22.

31. Durmuş B, van Rossem L, Duijts L et al. (2011) Breast-feeding and growth in children until the age of 3 years: the Generation R Study. Br J Nutr 105, 1704-1711.

32. Weng SF, Redsell SA, Swift JA et al. (2012) Systematic review and meta-analyses of risk factors for childhood overweight identifiable during infancy. Arch Dis Child 97, 1019-1026.

33. Skinner JD, Bounds W, Carruth BR et al. (2004) Predictors of children's body mass index: a longitudinal study of diet and growth in children aged 2-8 years. Int J Obes Relat Metab Disord 28, 476-482.

34. Scholtens S, Gehring U, Brunekreef B et al. (2007) Breastfeeding, weight gain in infancy, and overweight at seven years of age: the prevention and incidence of asthma and mite allergy birth cohort study. Am J Epidemiol 165, 919-926.

35. Harrington JW, Nguyen VQ, Paulson JF et al. (2010) Identifying the 'tipping point' age for overweight pediatric patients. Clin Pediatr 49, 638-643.

36. Dewey KG (1998) Growth characteristics of breast-fed compared to formula-fed infants. Biol Neonate $\mathbf{7 4}$, 94-105.

37. Kramer MS, Guo T, Platt RW et al. (2004) Feeding effects on growth during infancy. J Pediatr 145, 600-605.

38. Griffiths LJ, Smeeth L, Hawkins SS et al. (2009) Effects of infant feeding practice on weight gain from birth to 3 years. Arch Dis Child 94, 577-582.

39. Mihrshahi S, Battistutta D, Magarey A et al. (2011) Determinants of rapid weight gain during infancy: baseline results from the NOURISH randomised controlled trial. BMC Pediatr 11, 99.

40. Kramer MS, Moodie EE, Dahhou M et al. (2011) Breastfeeding and infant size: evidence of reverse causality. Am J Epidemiol 173, 978-983.

41. Kramer MS, Davies N, Oken E et al. (2018) Infant feeding and growth: putting the horse before the cart. Am J Clin Nutr 107, 635-639.

42. Druet C, Stettler N, Sharp S et al. (2012) Prediction of childhood obesity by infancy weight gain: an individual-level meta-analysis. Paediatr Perinat Epidemiol 26, 19-26.

43. Monasta L, Batty GD, Cattaneo A et al. (2010) Early-life determinants of overweight and obesity: a review of systematic reviews. Obes Rev 11, 695-708. 
44. Dubois L, Girard M, Girard A et al. (2007) Genetic and environmental influences on body size in early childhood: a twin birth-cohort study. Twin Res Hum Genet 10, 479-485.

45. Branum AM, Kirmeyer SE \& Gregory EC (2016) Prepregnancy body mass index by maternal characteristics and state: data from the birth certificate, 2014. Natl Vital Stat Rep 65, 1-11.

46. Muhlhausler BS, Gugusheff JR, Ong ZY et al. (2013) Nutritional approaches to breaking the intergenerational cycle of obesity. Can J Physiol Pharmacol 91, 421-428.
47. Daelmans B, Dewey K \& Arimond M (2009) New and updated indicators for assessing infant and young child feeding. Food Nutr Bull 30, S256-S262.

48. Azad MB, Vehling L, Chan D et al. (2018) Infant feeding and weight gain: separating breast milk from breastfeeding and formula from food. Pediatrics 142, e20181092.

49. Jessri M, Farmer AP, Maximova K et al. (2013) Predictors of exclusive breastfeeding: observations from the Alberta pregnancy outcomes and nutrition (APrON) study. BMC Pediatr 13, 77. 